\title{
BJRM
}

Bongaya Journal of Research in Management Volume 3 Nomor 2 Tahun 2020. Hal 01-06. e-ISSN: 2615-8868

Homepage: https://ojs.stiem-bongaya.ac.id/index.php/BJRM

\section{PENINGKATAN KEPUASAN PASIEN DITINJAU DARI ASPEK FASILITAS PADA RSUD SAWERIGADING KOTA PALOPO}

\section{IMPROVEMENT OF PATIENT SATISFACTION ASSESSED FROM FACILITIES ASPECT IN RSUD SAWERIGADING PALOPO}

\author{
Muh Rizal Halim ${ }^{1}$ dan Atia Kirana $\mathbf{W}^{2}$ \\ Sekolah Tinggi Ilmu Ekonomi Amkop Makassar, Indonesia \\ Email: rizal.halim.mrh@gmail.com
}

(Diterima: 19 November 2020; direvisi: 01 Desember 2020; dipublikasikan: 07 Desember 2020 )

(C2018 -Bongaya Journal for Research in Management STIEM Bongaya. Ini adalah artikel dengan akses terbuka dibawah licenci CC BY-NC-4.0 (https://creativecommons.org/licenses/by-nc/4.0/).

\begin{abstract}
This study aims to analyze how the ability to increase satisfaction in terms of the aspects of the facilities provided to patients at the Sawerigading Regional General Hospital, Palopo City, which in this study involved the number of research samples from as many as 100 patients who were met in a study conducted accidentally sampling, with a simple regression analysis technique, as for the research findings that show the results of the patient's assessment of the facilities provided by the staff of the Sawerigading Regional General Hospital have a positive and significant impact on satisfaction.
\end{abstract}

Keywords: Facilities, Satisfaction

\begin{abstract}
Abstrak
Penelitian ini bertujuan untuk menganalisis bagaimana kemampuan peningkatan kepuasan yang ditinjau dari aspek fasilitas yang diberikan kepada pasien pada Rumah Sakit Umum Daerah Sawerigading Kota Palopo, dimana pada penelitian ini melibatkan jumlah sampel penelitian dari sebanyak 100 orang pasien yang ditemui dalam penelitian yang dilakukan secara accidental sampling, dengan teknik analisis regresi sederhana, adapun temuan penelitian bahwa menunjukkan hasil dari penilaian pasien akan fasilitas yang diberikan oleh pihak Rumah Sakit Umum Daerah Sawerigading berdampak positif dan signifikan terhadap kepuasan.
\end{abstract}

Kata kunci: Fasilitas, Kepuasan

\section{PENDAHULUAN}

Upaya peningkatan kepuasan, maka salah satu aspek yang perlu dipertimbangkan adalah ketersediaan fasilitas kesehatan yang memadai. Dengan pemberian fasilitas yang memadai kepada pasien, maka akan membantu untuk meningkatkan rasa empati dari pasien maupun keluarga pasien tentang kondisi yang terjadi ketika konsumen menikmati jasa layanan kesehatan di rumah sakit (Jannah, 2017).
Berdasarkan data Kemenkes RI tahun 2018 jumlah tenaga kesehatan terbanyak yaitu perawat sebanyak 147.264 orang (45,65\%). Di Indonesia, perawat profesional baru mencapai 2\% dari total perawat yang ada. Angka ini jauh lebih rendah dibandingkan dengan Filipina yang sudah mencapai $40 \%$ dengan pendidikan strata satu dan dua (Sri, 2009). Tenaga perawat yang merupakan "the caring profession" mempunyai kedudukan penting dalam menghasilkan kualitas pelayanan kesehatan di rumah sakit, karena pelayanan yang 
diberikannya berdasarkan pendekatan bio-psikososial-spiritual merupakan pelayanan yang unik dilaksanakan selama 24 jam dan berkesinambungan merupakan kelebihan tersendiri dibanding pelayanan lainnya (Kemenkes RI, 2011). Dengan melihat pentingnya peran perawat dalam menjalankan tugasnya, maka perawat dituntut untuk lebih meningkatkan kemampuan dan kinerjanya. Untuk meningkatkan kinerja tersebut diperlukan adanya motivasi kerja, sikap kerja, kepemimpinan dan supervisi yang baik (Hafni, 2013).

Fakta yang ada di lapangan ditemukan perawat di RSUD Sawerigading kota Palopo memiliki beban kerja yang bervariasi, terutama petugas di rawat inap yang memerlukan kecepatan dalam menangani pasien dan cenderung melakukan aktifitas yang berulang. Hal ini tentunya dapat menimbulkan kelelahan kerja bahkan petugas berpotensi mengalami penurunan pelayanan akibat beban kerja yang tidak sesuai dengan kapasitasnya. Ketidak seimbangan antara beban kerja yang di terima perawat dan kapasitas individu dapat menimbulkan kelelahan dan kinerja yang meningkat, hal ini tentunya mempengaruhi kinerja perawat tersebut. Berdasarkan pra penelitian yang dilakukan oleh peneliti dengan mengobservasi langsung kegiatan perawat di ruang perawatan, peneliti tertarik untuk mengetahui pengaruh yang ditimbulkan oleh ketidak seimbangan antara beban yang diterima oleh petugas dengan kapasitasnya, yang akan berdampak buruk pada kesehatannya dan mengakibatkan petugas akan lebih mudah mengalami kelelahan yang nantinya akan mempengaruhi kinerja perawat itu sendiri.

Rumah Sakit Umum Daerah (RSUD) Sawerigading Kota Palopo, dalam kegiatan operasionalnya mengharapkan adanya kepuasan yang semakin tinggi dari pasien. Untuk itu, RSUD Sawerigading Kota Palopo telah berupaya untuk melengkapi fasilitas yang dimilikinya serta meningkatkan kinerja paramedis dalam pelayanan kepada pasien agar lebih optimal. Meskipun demikian, ditemukan suatu fenomena yang tidak sejalan dengan harapan pihak rumah sakit, antara lain tingkat kepuasan serta loyalitas pasien masih cenderung fluktuatif. Hal ini dapat dibuktikan dengan jumlah kunjungan pasien di RSUD Sawerigading Kota Palopo. Oleh karena itu, perlunya penelitian lebih lanjut apakah fasilitas dan kinerja paramedis yang mempengaruhi kepuasan pasien pada RS Sawerigading Kota Palopo.

\section{Rumusan Masalah}

Pada penelitian ini peneliti menarik pertanyaan penelitian Apakah Fasilitas berpengaruh terhadap Kepuasan Pasien pada RSUD Sawerigading Kota Palopo?

\section{Tujuan Penelitian}

Adapun tujuan penelitian ini adalah: mengetahui efek positif atau negatif dari fasilitas terhadap Kepuasan Pasien pada RSUD Sawerigading Kota Palopo.

\section{Tinjauan Pustaka}

Kepuasaan merupakan apa yang dirasakan oleh seseorang dimana apa yang ditawarkan dan diberikan sama dengan kenyataan (Suwanto \& Priansa, 2016), dengan kata lain seseorang akan merasa puas atau tidak puas tergantung pada apa yang ditemukan, dilihat dan dirasakan sama dengan apa yang ditawarkan, pandangan lain yang dikatakan oleh (Sedarmayanti, 2016) bahwa seseorang akan merasakan kepuasan dari apa yang telah ia temukan sesuai dengan kenyataan yang ada dilihatnya. Hal ini menjelaskan bahwa ukuran kepuasan dapat dihasilkan bilamana seseorang bisa meyakini antara apa yang ditawarkan sama dengan kenyataan.

Kepuasan adalah variabel yang menggambarkan hasrat seseorang yang tercapai akibat adanya kesesuaian antara harapan dan kenyataan (Sinambela, 2019).

Fasilitas adalah sarana yang diberikan bagi setiap instansi ataupun perusahaan dalam memberikan layanan terhadap apa yang hadir kepadanya sebagai suatu tempat untuk melakukan aktivitas (Listyawati, 2019). Fasilitas juga tidak terlepas sebagai salah satu faktor pendukung terhadap layanan yang ditawarkan kepada calon pembeli atau konsumen (Sulistiyana, 2015). Dapat dikatakan bahwa fasilitas adalah ukuran pencapaian terhadap kepuasan, dengan diadakannya fasilitas yang diberikan sebagai aspek pelayanan maka dapat berdampak terhadap kepuasan pasien.

\section{METODE}

Penelitian ini menggunakan pendekatan penelitian yang bersifat pada filsafat positivisme, 
yang mana ada sebab-akibat yang terjadi, penelitian ini menggunakan aplikasi google.doc untuk memudahkan peneliti mendapatkan data dari pasien Rumah Sakit Umum Daerah Sawerigading Kota Palopo. Ruang lingkup dan objek penelitian ini berada pada Rumah Sakit Umum Daerah Kota Palopo, dimana peneliti memilih objek pada RSUD Sawerigading.

Untuk dapat memberikan batasan pada penelitian ini, peneliti mengukur dari dua variabel yang diteliti di antaranya sebagai berikut:

1. Fasilitas

Fasilitas yang dimaksudkan dalam penelitian ini adalah fasilitas akan ketersediaan rumah sakit baik pada sisi dokternya, obatnya, alat kesehatannya dan sistem transaksi aktivitas pada rumah sakit

2. Kepuasan

Kepuasan pada penelitian ini, lebih melihat pada aspek yang dijadikan indikator seperti: mengenai sistem rumah sakit, kebutuhan ruang tunggu pasien, dan kemampuan rujukan kembali pasien.

Pada penelitian ini menggunakan seluruh pasien pada Rumah Sakit Umum Daerah (RSUD) Kota Palopo, namun pada penelitian ini peneliti tidak bisa menemukan total jumlah pasien pada Rumah Sakit Umum Daerah, namun untuk menemukan kepastian akan suatu sampel yang akan diteliti sebanyak 100 sampel, yang kemudian akan diberikan kuesioner terkait penelitian ini.

Penelitian ini menggunakan kuesioner sebagai bahan untuk mendapatkan informasi dari responden terkait kajian penelitian, dengan bahan ini maka model dalam pengumpulan data dengan Teknik wawancara, literatur pustaka dan kuisioner.

Analisis yang digunakan pada penelitian ini menggunakan Teknik analisis regresi linier sederhana dengan aplikasi SPSS.23 untuk melakukan running data yang telah ditabulasikan dari hasil kuesioner.

\section{HASIL DAN PEMBAHASAN}

Hasil penelitian ini akan menguraikan secara pengujian validitas dan reliabilitas data yang telah didapatkan dari hasil kuisioner yang telah dibagikan.

Temuan data hasil penelitian untuk uji validitas data dan reliabilitas data sebagai berikut terlihat pada tabel dibawah ini:

Tabel 1 Uji Validitas

Variabel Fasilitas (X)

\begin{tabular}{|c|c|c|c|}
\hline Pertanyaan/pernyataan & Pearson Correlation & $\mathrm{R}_{\text {tabel }}$ & Signifikansi \\
\hline Item 1 &, 710 &, 195 &, 000 \\
\hline Item 2 &, 570 &, 195 &, 000 \\
\hline Item 3 &, 696 &, 195 &, 000 \\
\hline Item 4 &, 736 &, 195 &, 000 \\
\hline Item 5 &, 662 &, 195 &, 000 \\
\hline Item 6 &, 748 &, 195 &, 000 \\
\hline
\end{tabular}

Sumber: Data Primer diolah.2020

Tabel 2.

Validitas Data

Kepuasan Pasien (Y)

\begin{tabular}{|l|l|l|l|}
\hline Pertanyaan/pernyataan & Pearson Correlation & $\mathrm{R}_{\text {tabel }}$ & Signifikansi \\
\hline
\end{tabular}




\begin{tabular}{|c|c|c|c|}
\hline Item 1 &, 491 &, 195 &, 000 \\
\hline Item 2 &, 580 &, 195 &, 000 \\
\hline Item 3 &, 644 &, 195 &, 000 \\
\hline Item 4 &, 798 &, 195 &, 000 \\
\hline Item 5 &, 884 &, 195 &, 000 \\
\hline
\end{tabular}

Sumber: Data Primer, diolah 2020.

Tabel 3.

Reliabilitas Data

\begin{tabular}{|c|c|c|c|}
\hline Variabel & Cronbach's Alpha & Standardized & Keterangan \\
\hline Fasilitas Kesehatan &, 771 & 0,60 & Realibel \\
\hline Kepuasan Pasien &, 765 & 0,60 & Realibel \\
\hline
\end{tabular}

Sumber: Data Primer, diolah 2020.

Tabel 4.

Model Summary

Model Summary ${ }^{b}$

\begin{tabular}{|l|r|r|r|r|}
\hline Model & \multicolumn{1}{|r|}{ R } & \multicolumn{2}{|l|}{ R Square } & \multicolumn{2}{|l|}{ Adjusted R Square } & Std. Error of the Estimate \\
\hline 1 &, $657^{\mathrm{a}}$ &, 432 &, 426 & 2,376 \\
\hline
\end{tabular}

a. Predictors: (Constant), Fasilitas Kesehatan

b. Dependent Variable: Kepuasan Pasien

Tabel 5.

Regresi Data

Coefficients $^{\mathrm{a}}$

\begin{tabular}{|rl|r|r|r|r|r|}
\hline \multicolumn{2}{|l|}{} & \multicolumn{2}{|c|}{ Unstandardized Coefficients } & \multicolumn{1}{c|}{$\begin{array}{c}\text { Standardized } \\
\text { Coefficients }\end{array}$} & \multicolumn{1}{c|}{ Sig. } \\
\cline { 3 - 5 } & \multicolumn{2}{|c|}{ B } & Std. Error & Beta & & \\
\hline \multirow{2}{*}{1} & (Constant) & 8,035 & 1,375 & & 5,842 &, 000 \\
& Fasilitas Kesehatan &, 492 &, 057 &, 657 & 8,634 &, 000 \\
\hline
\end{tabular}

a. Dependent Variable: Kepuasan Pasien

Data pengujian validitas pada variabel fasilitas yang didapatkan dari hasil penelitian menunjukkan bahwa seluruh indikator penelitian yang diberikan dalam pernyataan kuesioner menunjukkan nilai keseluruhan item data bermakna valid. Dengan dasar keputusan jika $r_{\text {hitung }}>r_{\text {tabel }}$ (uji 2 sisi dengan sig. 0,05) maka instrumen atau item-item pertanyaan berkorelasi signifikan terhadap skor total (dinyatakan valid) sedangkan jika $r_{\text {hitung }}<r_{\text {tabel }}$ (uji 2 sisi dengan sig. $0,05)$, maka instrumen atau item-item pertanyaan dinyatakan tidak valid. Sedangkan untuk variabel kepuasan ditemukan data juga bermakna valid dengan ukuran yang sama digunakan dalam menentukan validitas data.

Pengujian data selanjutnya pada tabel 3 adalah pengujian data untuk mengukur reliabel suatu data, dimana pada penelitian ini data dapat dikatakan realiable, ketika nilai Cronbach's Alpha lebih besar dari 0,60. Inilah yang menjadi dasar keputusan dapat dikatakan realibel. Dari hasil menunjukkan bahwa nilai dari Cronbach's 
Alpha dari masing-masing variabel yang diukur diantaranya variabel fasilitas kesehatan bernilai $0.771>0.6$ yang bermakna data reliabel, sedangkan pada variabel kepuasan pasien menunjukkan nilai sebesar $0.765>0.6$ yang berarti bahwa data yang didapatkan bermakna reliabel.

Pengujian data dengan mengukur tingkat validitas dan reliabilitasnya telah menunjukkan hal yang baik selanjutnya peneliti akan mengukur tingkat koefisien korelasi atau nilai dari R square dari data yang telah diolah dengan menggunakan aplikasi SPSS.23.

Pengujian ini untuk mengetahui lemah kuatnya hubungan yang diberikan dari variabel fasilitas kesehatan pada Rumah Sakit Umum Daerah Sawerigading Kota Palopo. Dimana data yang telah running didapatkan hasilnya terlihat pada tabel 4. di atas. Data di atas menunjukkan bahwa besaran nilai dari $\mathrm{R}$ square adalah 0.432 atau sebesar $43.2 \%$ yang bermakna kuat, dimana fasilitas mampu memberikan hubungan yang kuat terhadap kepuasan pasien, sedangkan untuk nilai adjuste $R$ square sebesar 0.426 atau $42.6 \%$ yang bermakna bahwa jika terjadi perubahan dari nilai $\mathrm{R}$ square, maka nilai adjust $R$ square yang menunjukkan keakuratan hubungan, dimana keakuratan hubungan dari fasilitas kesehatan terhadap kepuasan pasien sebesar $42.6 \%$ dan sisanya merupakan faktor lain yang tidak diteliti pada penelitian ini.

Pada tabel 4.5 menunjukkan data hasil output data regresi dimana didapatkan hasil untuk nilai konstan (a) sebesar 8.035 dan nilai regresi atau pengaruh dari fasilitas kesehatan terhadap kepuasan pasien (b) bernilai sebesar 0.492, dari data ini maka dapat diturunkan persamaan dalam regresi linier sederhana sebagai berikut:

$$
\begin{gathered}
Y=a+b x \\
Y=8.036+0.492 x
\end{gathered}
$$

Hasil dari turunan persamaan di atas, kemudian peneliti menjelaskan, bahwa nilai konstan sebesar 8.035 memiliki makna jika variabel fasilitas kesehatan konstan atau 0 maka nilai konsistensinya sebesar 8.034, sedangkan koefisien regresi dari fasilitas kesehatan sebesar 0.492 yang bermakna bahwa jika terjadi perubahan 1 poin dari fasilitas kesehatan, maka kepuasan pasien meningkat sebesar 0.492 atau sebesar $49.2 \%$ yang berarti nilai bermakna positif.
Pengukuran signifikansi dari penelitian ini berdasarkan pada pengukuran dasar dengan menggunakan nilai 0.05 , yang mana jika taraf signifikansi 0.05 < dari hasil maka bermakna signifikan, sebaliknya jika nilai taraf signifikansi $0.05>$ nilai hasil hitung maka tidak signifikan. Dari hasil penelitian yang ditunjukkan pada tabel 5. di atas nilai probabilita atau taraf signifikansi yang didapatkan dalam penelitian ini sebesar 0.000 atau dengan kata lain $0.000<0.05$, yang bermakna bahwa fasilitas kesehatan berpengaruh positif dan signifikan terhadap kepuasan pasien pada Rumah Sakit Umum Daerah Sawerigading Kota Palopo.

\section{PEMBAHASAN}

Temuan penelitian ini menunjukkan bahwa secara data penelitian yang disebarkan memiliki makna valid dan reliabel, dengan perhitungan dasar pengambilan keputusan. Dari data uji yang telah dilakukan menunjukkan fasilitas yang ditawarkan oleh Rumah Sakit Umum Daerah Sawerigading Kota Palopo memiliki hubungan yang kuat sebesar $42.6 \%$ terhadap kepuasan pasien yang berobat. Hal ini menunjukkan bahwa perhatian pengelola Rumah Sakit kepada pasien adalah hal yang utama dimana sisi pelayanan adalah bagian terpenting. Pada pengujian regresi menunjukkan hasil bahwa fasilitas kesehatan berpengaruh positif dan signifikan terhadap kepuasan pasien. Dapat dikatakan bahwa fasilitas adalah kekuatan dalam suatu pelayanan sehingga peranan fasilitas mampu memberikan efek yang positif pada pasien yang berobat pada Rumah Sakit Umum Daerah Sawerigading Kota Palopo. Hal ini didukung dengan pandangan dari teori yang dikemukakan oleh Fasilitas adalah sarana yang diberikan bagi setiap instansi ataupun perusahaan dalam memberikan layanan terhadap apa yang hadir kepadanya sebagai suatu tempat untuk melakukan aktivitas (Listyawati, 2019). Penelitian ini juga didukung oleh penelitian sebelumnya diantaranya (Srijani \& Hidayat, 2018) yang mengatakan dalam hasil penelitiannya fasilitas yang diberikan hotel berpengaruh positif dan signifikan terhadap kepuasan tamu. Selain penelitian di atas ada pula penelitian yang dilakukan oleh (Marhanah \& Wahadi, 2016) yang mengatakan bahwa dengan keberadaan fasilitas sebagai alat 
pendukung akan mendorong rasa puas bagi tamu dalam berkunjung.

\section{SIMPULAN DAN SARAN}

Pemaparan hasil penelitian diatas, maka dapat ditarik simpulan dalam penelitian ini yang mana fasilitas berpengaruh positif dan signifikan terhadap kepuasan pasien pada Rumah Sakit Umum Daerah Sawerigading Kota Palopo dan memiliki hubungan yang erat dalam berkontribusi memberikan kepuasan pasien yang menjalani pengobatan.

Adapun saran peneliti, agar pihak pengelola Rumah Sakit Umum Daerah Sawerigading Kota Palopo mempertahankan dan menganalisis faktor lain yang dapat mendukung upaya pengembangan kepuasan pasien dalam menjalani proses pengobatan di rumah sakit tersebut.

\section{DAFTAR RUJUKAN}

Listyawati, I. H. (2019). Pengaruh Fasilitas Wisata, Citra Destinasi, dan Kepusan Terhadap Loyalitas Wisatawan. Jurnal Manajemen Administrasi.

Marhanah, S., \& Wahadi, W. H. (2016). Pengunjung Di Taman Margasatwa the Influence of Tourism Facilities and Quality of Service To Customer Satisfaction At Taman Margasatwa. Jurnal Manajemen Resort Dan Leisure.

Sedarmayanti. (2016). Manajemen Sumber Daya Manusia. In Manajemen Sumber Daya Manusia.

Sinambela, L. P. (Prof. D. (2019). Manajemen Sumber Daya Manusia. In PT.Bumi Aksara.

Srijani, N., \& Hidayat, A. S. (2018). Pengaruh fasilitas terhadap kepuasan pelanggan di aston madiun hotel \& conference center. Wiga: Jurnal Penelitian Ilmu Ekonomi. https://doi.org/10.30741/wiga.v7i1.336

Sulistiyana, R. (2015). Pengaruh Fasilitas Wisata Dan Harga Terhadap Kepuasan Konsumen (Studi Pada Museum Satwa). Jurnal Administrasi Bisnis S1 Universitas Brawijaya.

Suwanto, \& Priansa, D. J. (2016). Manajemen SDM dalam Organisasi Publik dan Bisnis.pdf. In ALFABETA. 